\section{VECTORS OF MALARIA}

\section{The Anophelinae of Africa South of the Sahara} (Ethiopian Zoogeographical Region.) Second edition. (Publications of the South African Institute for Medical Research, No. 54.) By M. T. Gillies and Botha de Meillon. Pp. 343. (The South African Institute for Medical Research: Johannesburg, 1968.) n.p.

In the twenty-one years that have elapsed since the first edition of "De Meillon" was published, a considerable volume of data has accumulated on the systematics, distribution and biology of the anopheline mosquitocs of the Ethiopian geographical region (or, as the authors now wisely call it in their title, "Africa South of the Sahara") The stimulus for much of the field work that has yiclded this new information is the activity that has been generated, largely through the guidance of the World Health Organization, in the control of malaria throughout this region. In the course of studies on malaria and its vectors in various countries many new species of Anopheles have been discovered and much has been learned of their natural history and importance as disease vectors. The 101 species and an additional 8 subspecies described in the present work may be compared with the 77 species plus 20 subspecies or varieties in the original publication.

Sinco 1947, some 13 subspecies ( 2 of them recently described) have been raised to specific rank while 4 known species and 2 varieties have been treated as subspecies. Many "species", "varieties" and soveral "subspecies" described since 1947 have been sunk as synonyms. The main object of the present work, which has been largely rewritten and eonsiderably enlarged (343 as against the original 272 pages), is to assist malaria entomologists. New and improved keys and synopses of the diagnostic characters of the insects have now been prepared, while country lists and distribution maps provide a further ready reference to species that the entomologist is likely to encounter in his particular locality. His use of the keys is facilitated by the inclusion of excellent, clearly labelled figures of the external morphological features of all stages and the internal anatomy of the imagines, a knowledge of which in many species of this genus is essential for their correct identification. Particular attention is made to the most important malaria vectors, Anopheles gambiae and the species complex in which it is centred, to $A$. funestus with its close relatives and to the dozen or so secondary or incidental vectors. In the concluding chapter on zoogcography a useful vegetation map of Africa replaces the map that, in the original edition, was notable mainly for the large number of interrogation marks. Theso reflectcd accurately our relatively poor knowledge at that time of this aspect of the African anopheline fauna. The constructively critical manner in which the authors have sieved all the available data to present their present comprehensive manual is evident throughout this work. The standard of the figures and the newly set typo is first class.

This new edition is sure to be welcomed not only by all engaged in the control of malaria in Africa and elsewhero but also by those concerned with more general aspects of mosquitoes, their systematics, distribution and biology.

W. Peters

\section{ELECTRICAL SURGES}

\section{Surge Phenomena in Electrical Machines}

By B. Heller and A. Veverka. English translation edited by J. S. Vosper. Pp. 9+501. (Iliffe: London, 1968.) $95 s$.

The problems of surge phenomena and the generation of surges, both artificially in the laboratory and by natural means, constitute one of the oldest branches of electrical technology. It was Benjamin Franklin who first investigated lightning systematically, and Steinmetz first set up an "artificial lightning" generator in the laboratories of General Electric in the last years of the past century. Stcinmetz's objective was to create surges in the laboratory in order to ascertain the performance of plant which was then being developed for electrical power systems and which would be subjected to lightning in the normal course of service.

Today, the problem is not so much a question of lightning strikes on power systems, as voltages have risen throughout the world; the overvoltages generated internally to the system by switching have been found to be more significant than those caused by atmospheric lightning. It follows, furthermore, that the internally generated overvoltages tend to be of a higher level than those otherwise caused. In consequence, increased attention has to be paid to the performance of plant connected to electrical power systems and to the problems of analysis of surge phenomena of transmission systems. This volume is concerned with the former of these two eategories, and not with the analysis of transmission phenomena as such. Nevertheless, it is a very broad book. It deals with the performance of coil arrangements with and without iron, and it then has a very substantial section, approximately one half of the book, on the power transformer. There is no doubt that the power transformer is one of the most exposed items in an electrical sense and, at the same time, one of the most singularly expensive items of a power system. In contrast to the detailed treatment given to the transformer, however, the analysis of surge phenomena in rotating machines receives only slight attention; it could be argued that the problem is not so important. As plant sizes riso, the tendeney is always to associate a "unit" transformer with the given and large generator in question. If there is to be any damage to the generating plant as a result of surges which have penetrated as far as the main bus-bar system, then it is likely that it will be the transformer which will suffer. Naturally, an important part of the theory and practice of protecting electrical power systems is the appropriate surge divertor and lightning arrestor apparatus which will be situated closer to the power system than the main bus-bars; this apparatus is designed to minimize the damage to unit transformers and for that matter any other transformers which are supplying directly to the system. These questions are all well treated.

This book, however, is not concerned solely with the problems of plant as its name implies. Very large scetions toward the end of the book are given over to surge voltage generators, particularly the Marx eircuit, which is in general use throughout the world. 'There is also a detailed treatment of the problem of surge voltage dividers; many appendices deal with the problems of determining freo oscillations in various winding arrangements, earthed and unearthed, the determination of voltage gradients in coils, and certain computations of initial voltage distribution of transformers which have layer windings.

The book was first published in 1954. A section has now been added on the use of digital computers for the analysis of surge phenomena; this is not, however, a particularly satisfactory chapter, and has the general appearance of a rather ill-considered addition. Ono final point of general interest is that, short of going through the complete International Conference on Large-Electric Systems (CIGRE) biographies, this book contains ono of the most comprehensive international lists of references that has ever been assembled. There are 314 items. altogether, from American, French, British, German, Russian, Italian and Czech sources.

The mathematical treatment given in the book is quite adequate. It is, of course, particularly detailed in the chapter eoncerned with computer analysis of surge phenomena in transformer windings, but it is deficient in the longish section concerned with the modelling of 